\title{
Urticaria and angioedema associated with SARS-CoV-2 infection
}

\author{
Jonathan S. Zipursky MD, David Croitoru MD
}

Cite as: CMAJ 2021 September 7;193:E1390. doi: 10.1503/cmaj.211087

A 27-year-old woman developed fever, headache and diarrhea; testing by polymerase chain reaction confirmed SARS-CoV-2 infection. One week later, she developed a migratory, pruritic urticarial rash. She visited an emergency department and was treated with prednisone $50 \mathrm{mg}$ and hydroxyzine $10 \mathrm{mg}$, as necessary, with some improvement.

Over the next week, however, the patient's rash worsened and she developed facial swelling and chest tightness, which led her to present to our emergency department. She had no history of urticaria and no new drug or environmental exposures. On examination, she had erythematous plaques (wheals) on her face, limbs, trunk, palms and soles, without postinflammatory hyperpigmentation or purpura (Figure 1), and angioedema of her lips (Appendix 1, available at www.cmaj.ca/lookup/ doi/10.1503/cmaj.211087/tab-related-content). Emergency department physicians treated her with epinephrine and diphenhydramine because of the angioedema. We admitted the patient for monitoring, and prescribed cetirizine $20 \mathrm{mg}$ twice daily. We attributed her symptoms to acute SARS-CoV-2 infection. We discharged her from hospital after 1 day; on assessment 12 weeks later, she was still having episodes of urticaria and taking cetirizine as needed.

The most likely diagnosis was chronic spontaneous urticaria triggered by SARS-CoV-2, but other considerations were urticarial vasculitis and chronic inducible urticaria. Urticaria is commonly triggered by viral and bacterial infections, including herpes simplex virus, cytomegalovirus, Epstein-Barr virus, HIV and mycoplasma. ${ }^{1}$ It commonly

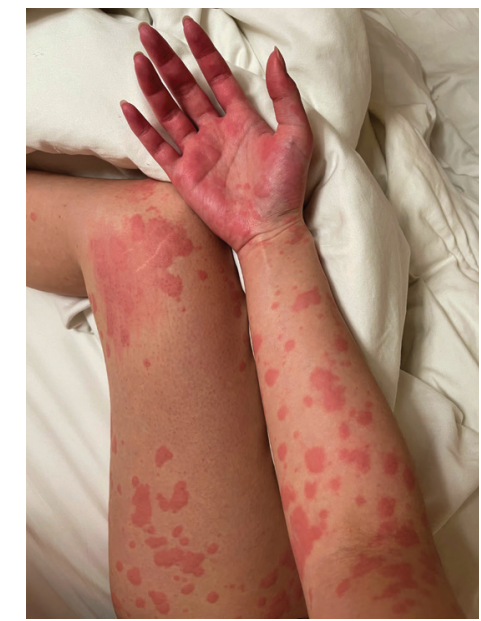

Figure 1: Raised erythematous plaques (wheals) on the palm, arm and leg of a 27-year-old woman with SARS-CoV-2 infection.

precedes or occurs concurrently with typical COVID-19 symptoms, but can rarely occur after other symptoms have resolved. ${ }^{2}$ Urticaria, perniolike lesions and morbilliform exanthems are the most common cutaneous manifestations of COVID19. ${ }^{3}$ The pathophysiology may be related to complement and mast cell activation by the direct cytopathic effects of SARS-CoV-2, as well as cytokine signalling. Furthermore, SARS-CoV-2 downregulation of angiotensin-converting enzyme 2, leading to increased levels of angiotensin II, may exacerbate vasoconstriction or vascular permeability. ${ }^{4}$

In patients who present with new-onset urticaria or angioedema, clinicians should ask about infectious disease symptoms, including those related to COVID-19. We do not suggest routine SARS-CoV-2 testing in patients who are otherwise asymptomatic. Symptomatic urticaria related to SARS-CoV-2 infection should be treated with second- and third-generation nonsedating antihistamines, up to 4 times the usual dose, if needed. ${ }^{5}$ Low-dose systemic corticosteroids can be considered in severe cases. ${ }^{5}$

\section{References}

1. Genovese G, Moltrasio C, Berti E, et al. Skin manifestations associated with COVID19: current knowledge and future perspectives. Dermatology 2021;237:1-12.

2. Algaadi SA. Urticaria and COVID-19: a review. Dermatol Ther 2020;33:e14290.

3. Freeman EE, McMahon DE, Lipoff JB, et al. The spectrum of COVID-19-associated dermatologic manifestations: an international registry of 716 patients from 31 countries. J Am Acad Dermatol 2020;83:1118-29.

4. Vaduganathan $M$, Vardeny $\mathrm{O}$, Michel $\mathrm{T}$, et al. Renin-angiotensin-aldosterone system inhibitors in patients with Covid-19. N Engl J Med 2020;382:1653-9.

5. Abuelgasim E, Dona ACM, Sondh RS, et al. Management of urticaria in COVID-19 patients: a systematic review. Dermatol Ther 2021;34:e14328. doi: 10.1111/dth.14328.

Competing interests: Jonathan Zipursky reports payments for medicolegal opinions regarding the safety and effectiveness of drugs, outside the submitted work. No other competing interests were declared.

This article has been peer reviewed.

The authors have obtained patient consent.

Affiliations: Department of Medicine (Zipursky, Croitoru), University of Toronto; Department of Medicine (Zipursky), Sunnybrook Health
Sciences Centre; Division of Clinical Pharmacology and Toxicology (Zipursky) and Institute of Health Policy, Management and Evaluation (Zipursky) and Division of Dermatology (Croitoru), University of Toronto, Toronto, Ont.

Content licence: This is an Open Access article distributed in accordance with the terms of the Creative Commons Attribution (CC BY-NC-ND 4.0) licence, which permits use, distribution and reproduction in any medium, provided that the original publication is properly cited, the use is noncommercial (i.e., research or educational use), and no modifications or adaptations are made. See: https://creativecommons. org/licenses/by-nc-nd/4.0/

Acknowledgement: The authors thank Donald Redelmeier for helpful comments on earlier versions of the manuscript.

Correspondence to: Jonathan Zipursky, jonathan.zipursky@mail.utoronto.ca 